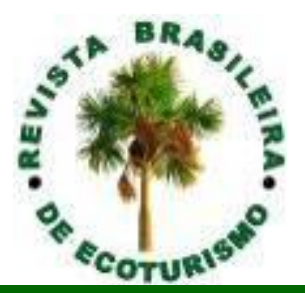

\title{
Projeção de rotas ciclo turísticas no interior de Pernambuco
}

\section{Projection of cyclo turistic routes inside Pernambuco, Brazil}

\author{
Thales Ramon Queiroz Bezerra, Emilly Cristine de Aguiar Costa
}

\begin{abstract}
RESUMO: O ciclo turismo é uma atividade turística realizada com bicicletas, que podem trazer vantagens na área da saúde e da economia, podendo gerar trabalho, emprego e renda para as comunidades contempladas com a criação de rotas. 0 trabalho teve como objetivo principal conhecer as práticas e as características do ciclo turismo em Pernambuco e propor a criação de rotas ciclo turísticas na Zona da Mata Sul do estado, que possui o segundo menor índice de incidentes com bicicletas em Pernambuco. Desta forma, utilizou-se de formulários para entender: o perfil do praticante no estado; o que eles consideram importantes numa rota; entrevistar especialistas para definir critérios, hierarquizá-los para definir os municípios postulantes. Para isso, utilizou-se o método "Analytic Hierarchy Process" - AHP, que entre outras coisas, auxilia na tomada de decisão. Os resultados mostraram que dos 24 municípios da região estudada, sete deles reuniam as melhores condições para implantação de uma rota, em função das riquezas naturais, culturais e infraestrutura, que foram considerados critérios indispensáveis pelos entrevistados. Desta forma foi possível a projeção de 3 rotas ciclo turísticas que podem ajudar na potencialização da economia local, se transformados em um produto a ser comercializado por agências de turismo e gestores.
\end{abstract}

PALAVRAS CHAVE: Sustentabilidade; Regionalização do Turismo; Ecoturismo.

ABSTRACT: Cycle tourism it is a bicycle recreational activity that can provides some health benefits and be economically profitable. The creation of City routes potentially generates new job opportunities for the communities in the vicinities of these routes. The aim of this study was to identify the characteristics of the practitioners of this activity in Pernambuco State and suggest the creation of new cycle touristic routes on Southern of Zona da Mata once it is rated as the second lower incidents area with bicycle riders in Pernambuco. To assess and understand the user's profile, filling forms were utilized in the State to identify what the users consider as important in a route. Specialists were interviewed to define criteria's to set it up in a hierarchy as postulant County. The "Analytic Hierarchy Proccess" - AHP is a reliable tool to help us to take a final decision. The results showed 7 out 24 Counties assessed has the best conditions for a route implantation due to Natural riches, cultural potentiality and infra structure that was considered by the interviewed population as an indispensable criteria's. Following this, 3 touristic cycle routes can be suggested to help potentialize the local economy if transformed in a tourism product by the Tourism agencies and local Government.

KEYWORDS: Sustenability; Regional Tourism; Ecotourism.

Sociedade Brasileira de Ecoturismo. Rua Dona Avelina, 225, Vila Mariana, São Paulo, SP - Brasil. 


\section{Introdução}

Em países tropicais, de forma geral, a exploração de turismo de sol e mar faz com que outras riquezas e vocações possam ser pouco utilizadas, o que traz consigo não somente perdas econômicas (MARANHÃO; AZEVEDO, 2019), mas também sentimento de frustração pelos profissionais e agentes de turismo (MERCE et al., 2012). Os segmentos do turismo que estão mais em contato com a natureza, como o ecoturismo, turismo verde ou turismo de aventura, valorizam mais o meio ambiente (CAMARGO et al.,2011), geram maior integração com a comunidade receptora (GOUVEIA et al., 2014) e ajudam a fazer uma atividade mais sustentável (MARTINS, 2012).

Em Pernambuco é notado um trabalho recente, por parte dos gestores públicos, com o propósito de aliviar a concentração do turismo na capital, Recife (SEBRAE, 2011). Isso traz como consequência, a geração de renda, emprego, trabalho, fixa o rurícola na terra (LEE, 2009) e dessa forma, faz com que a distribuição das riquezas geradas pela atividade se consolide de forma prática (MERCE et al., 2012). Contudo, ainda faltam elementos que permitam uma maior diversidade das opções de lazer e recreação em locais longe do litoral, em função, entre outras coisas, da falta de estrutura, causada pelos poucos investimentos públicos experimentados até o momento.

O ciclo turismo, apesar de ser considerada uma nova atividade turística, está se expandindo mundialmente, sendo responsável por trazer vantagens na área da saúde e da economia, pois apresenta benefícios como melhoria das articulações; reforço do sistema imunológico; melhoria a nível cardiovascular; aumento da capacidade respiratória; aceleração do metabolismo; controle de peso, regula o estresse e gera bem-estar geral (REVISTA BICICLETA, 2012).

Pelo lado econômico, um estudo realizado em 2018 pela European Cyclists' Federation (ECF), responsável pela rede europeia de rotas ciclistas EuroVelo, afirma que o uso da bicicleta beneficia a economia em 205 bilhões de euro por ano naquele continente. Entre os benefícios encontram-se a geração de 650 mil empregos, fortalecimento do comércio e economia local.

Já o Relatório da London School of Economics (2010), mostra o ciclo turismo gerando uma economia de 3 bilhões de libras no Reino Unido, criando cerca de 1,3 milhões de novos ciclistas, construindo cerca de 200 mil novos quilômetros de ciclovias, ciclo faixas e ciclo rotas e empregando aproximadamente 23 mil pessoas.

No Brasil, entre 2001 e 2011, foram investidos 20,2 milhões de reais para a construção de ciclovias em 53 municípios (MINISTÉRIO DO TURISMO, 2011). Já para o Ministério das Cidades, há $2.500 \mathrm{~km}$ de ciclovias e ciclo faixas no País, mas que é considerado um tapete curto, para as 75 milhões de bicicletas que existem hoje no Brasil. Dados de 2018 mostram que a malha ciclo viária do país cresceu $133 \%$ em quatro anos (VELASCO et al., 2018) e em Recife são mais de $170 \mathrm{~km}$ de rotas ciclo viárias permanentes (PCR, 2020). 
ciclo turismo possuí diversas rotas e circuitos no Brasil, dentre as quais se destacam: Caminho da Fé (SP-MG); Circuito Vale Europeu de Ciclo turismo (SC); Estrada Real (MG-RJ-SP) e Caminho do Sol (SP).

Notou-se a pouca existência de informação, principalmente acadêmica, sobre o ciclo turismo no estado de Pernambuco, além disso a maioria das rotas e circuitos estão localizadas no Sudeste e Sul do país. Tal fato incentivou o interesse para desenvolver uma temática que, por ser recente, carece de estudos, e assim poder contribuir na área e tornar a atividade mais presente no Nordeste do Brasil.

Portanto, os objetivos do trabalho é conhecer as práticas e as características do ciclo turismo em Pernambuco e propor uma rota no estado para fomento a regionalização da atividade. Definir os principais critérios para criação de uma rota ciclo turística em Pernambuco e conhecer os municípios da Região da Mata Sul do estado que apresentam potencial para construção dessas rotas.

\section{Material e Métodos}

Realizou-se um diagnóstico do ciclo turismo em Pernambuco para compará-lo com um levantamento realizado pelo observatório do Ciclo turismo, entre 2008 e 2018 do perfil nacional. O trabalho em Pernambuco, contou com entrevistas a dois grupos de ciclo turistas: "Circuito Ecopedal de Pernambuco" e "Loucos por Bike PE", além da empresa "BICITOUR Brasil Ciclo turismo".

Com relação a primeira e única rota ciclo turística em Pernambuco, a "Rota do Agreste", entrevistou-se o ex-Gerente de Mobilidade da Secretaria de Turismo, Esporte e Lazer e antigo gestor do programa "Pedala PE", e a nova Gerente de Mobilidade do estado, para coleta dos dados.

Para eleger os municípios pernambucanos propícios para a projeção de rotas, perguntou-se aos participantes da pesquisa, quais critérios deveriam fazer parte desse percurso. Após a escolhas dos critérios, esses dados passaram por um processo de hierarquização, a qual foi feita, a partir de quatro matrizes, preenchidas por pesquisadores da Universidade Federal de Pernambuco (UFPE). A avaliação consistiu na comparação dos critérios e subcritérios aos pares. O julgamento sintetizou a resposta de duas perguntas: $1^{\mathrm{a}}$ - qual dos dois elementos é mais importante e a $2^{\mathrm{a}}$ - com que intensidade. Para isso, foi usada uma escala de 1 a 9 (Tabela 1) (SAATY, 1980).

Tabela 1: Valores de grandeza para comparação par a par entre critérios.

Table 1: Values of magnitude for peer comparison between criteria.

\section{Pontuação principal}

1

3

5

7

9

$2,4,6,8$
Definição da pontuação

Mesma importância

Pouca importância

Grande importância

Importância elevada

Importância absoluta

Valores intermediários entre pontuações principais

Source: elaborated by the authors (2019)

523 Revista Brasileira de Ecoturismo, São Paulo, v.14, n.4, nov 2021-jan 2022, pp. 521-538. 
Ao final do preenchimento das matrizes, foi necessário avaliar a coerência ou lógica matemática dos entrevistados, a partir do uso de um índice de consistência randômica, segundo Saaty (2000). Esse tipo de verificação pretende verificar, por exemplo: "Se um critério $A>B$ e um critério $B>C$, o critério $C$ nunca poderá ser maior que $A$ ". Para um determinado número de critérios, existe um índice randômico (IR) de verificação (se existem 9 critérios sendo comparados entre si, o IR tem que ser inferior a 1,45 (Tabela 2).

Tabela 2: Índices Randômicos para cálculo do índice de consistência.

Table 2: Ramdom indexes for calculating the consistency index.

\begin{tabular}{|c|c|c|c|c|c|c|c|c|c|c|}
\hline $\mathrm{N}$ & 1 & 2 & 3 & 4 & 5 & 6 & 7 & 8 & 9 & 10 \\
\hline IR Randômico & 0 & 0 & 0,58 & 0,9 & 1,12 & 1,24 & 1,32 & 1,41 & 1,45 & 1,49 \\
\hline
\end{tabular}

Por fim, todas as transformações dos dados, desde o preenchimento inicial da matriz comparativa entre os critérios, até a verificação da coerência, podem ser acompanhadas na Tabela 3.

Tabela 3: Exemplo de preenchimento de matriz, transformações de dados e cálculo dos indicadores.

Table 3: Exemple of matrix filling, data transformations and calculations of indicators.

\begin{tabular}{|c|c|c|c|c|c|c|c|c|c|c|c|c|c|c|c|}
\hline & \multicolumn{3}{|c|}{ Valor } & \multicolumn{3}{|c|}{ Valor Decimal } & \multicolumn{3}{|c|}{ Valor Normalizado } & \multicolumn{6}{|c|}{ Indicadores } \\
\hline & D1 & D2 & D3 & $\begin{array}{l}\text { D } \\
1\end{array}$ & D2 & D3 & D1 & D2 & D3 & $\begin{array}{l}\text { Auto } \\
\text { Vetor }\end{array}$ & $\begin{array}{l}\text { V. } \\
(\%)\end{array}$ & $\begin{array}{l}\lambda- \\
\max \end{array}$ & IC & IR & RC \\
\hline D1 & 1 & $1 / 3$ & $1 / 5^{(2)}$ & 1 & 0,33 & 0,2 & 0,11 & 0,06 & 0,13 & 0,41 & 10,07 & 3,13 & 0,06 & 0,58 & 0,1 \\
\hline D2 & $3^{(1)}$ & 1 & $1 / 4$ & 3 & 1 & 0,25 & 0,33 & 0,18 & 0,17 & 0,91 & 22,55 & & & & \\
\hline D3 & 5 & 4 & 1 & 5 & 4 & 1 & 0,56 & 0,75 & 0,68 & 2,71 & 67,38 & & & & \\
\hline Total & & & & 9 & 5,33 & 1,45 & & & & 4,03 & 100,00 & & & & \\
\hline
\end{tabular}

1 - O critério D2 é pouco mais importante (valor 3), que o critério D1

2 - O critério D3 é considerado de grande importância com relação ao critério D1

Fonte: Bezerra (2011), adaptado pelos autores (2019).

Source: Bezerra, (2011), adapted by the authors (2019).

Legenda:

D1/ D2/ D3: Destinos pré-estabelecidos na fase de eleição dos melhores municípios da Mata Sul de PE;

Valor: Números inteiro quando o critério linha é mais importante que o da coluna, sendo os fracionados, o critério coluna mais importante que o da linha (considerando a tabela 1);

Valor Decimal: Valores fracionados em formato decimal;

Valor Normalizado: produto da divisão do valor de cada dado da matriz no formato decimal pelo somatório da coluna (ex.: D1 $(1 / 9=0,11)$;

Auto Vetor: é calculado com a média geométrica da linha de cada critério;

V. N. (vetor normalizado): Auto Vetor/Total (D $1=0,41 / 4,03=10,07$ );

$\lambda$-max (Autovalor Máximo): média dos valores da matriz normalizada e o somatório da coluna da matriz decimal;

IC (Índice de Consistência $)=(\lambda \max -n) /(n-1), I C=(3,13-3) / 2=0,06$;

IR (Índice Randômico), sugerido por Saaty (1980) para matriz de ordem 3 é igual a 0,58 ;

RC (Razão de Consistência) $=$ IC/IR, sendo $=(0,06 / 0,58)=0,10$. O RC deve ser abaixo de 20\% (FAVRETTO; NOTAR, 2016). 
Para criação das rotas, considerando os critérios escolhidos pelos entrevistados, fez-se um levantamento de dados municipais, através do Inventário da Oferta Turística de Pernambuco - INVTUR PE.

Foram definidos os 5 principais subcritérios, a partir de uma média ponderada entre os percentuais das matrizes dos critérios e dos subcritérios. $\mathrm{Na}$ sequência, foram criados grupos de elementos para associar os municípios da mata sul de Pernambuco a esses subcritérios. Por fim usou-se esses resultados para criar os mapas, demonstrando possíveis locais para implantação das rotas e como elas poderia se interligar, utilizando-se o QGIS, Google Earth e o Google Maps.

\section{Resultados e Discussão}

\section{Comparação entre perfil do ciclo turista nacional e o de Pernambuco}

Os dados do levantamento de 2008 e 2018 para o perfil nacional mostraram um público majoritariamente masculino, igualmente ao encontrado em Pernambuco (Figura 1A). No quesito faixa etária os dados comparativos entre o nacional se detiveram ao ano de 2018, que assim como os dados de PE, possuem sua maior parte dos participantes entre 30 e 50 anos (Figura 1B).
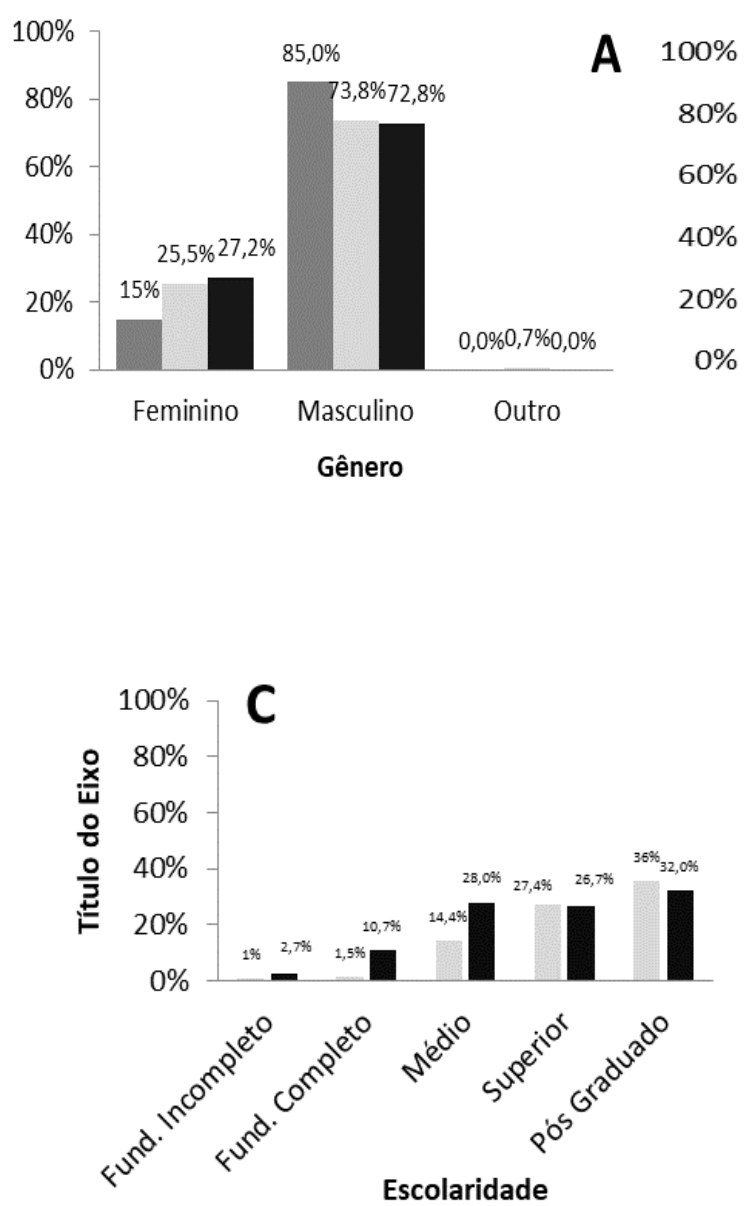

A $100 \%$

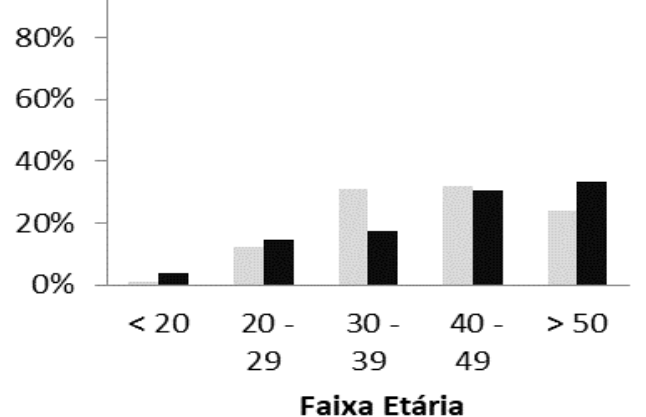

$2008 \quad 2018$ - 2019

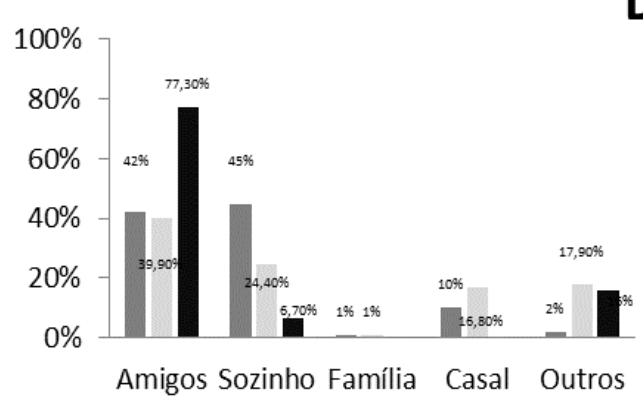

Preferência de realização de viagem

Figura 1 - Perfil comparativo entre praticantes nacional e de Pernambuco (PE). Figure 1: Comparative profile between national and Pernambuco practitioners (PE). Fonte: elaborado pelos autores (2019).

Source: elaborated by the authors (2019). 
Com relação a escolaridade, Pernambuco tem mais praticantes do ensino médio e se iguala ao perfil nacional nos grupos de graduados e pósgraduados (Figura 1C). Com relação as preferências sobre de que forma costumam fazer suas viagens os resultados variam entre os perfis nacionais, mas o pernambucano viaja mais com os amigos (Figura 1D).

Quanto as experiências em ciclo viagens, no âmbito nacional, em 2008, 70\% responderam nas entrevistas possuírem experiências com ciclo turismo e em 2018 esse percentual cai para 49,9\%, que afirmam ter viajado no Brasil nos últimos cinco anos.

Sobre a motivação do ciclo turista quando vai realizar as viagens, em 2018, poderia se escolher mais de uma opção e por isso, a soma das porcentagens ultrapassa os $100 \%$. A alternativa que sempre ficou como um dos maiores resultados, é a de "Natureza/ paisagem", sendo possível afirmar que esse se caracteriza com um critério consideravelmente relevante numa rota. Em Pernambuco, o praticante também gostaria de conhecer novos lugares (Tabela 4).

Tabela 4: Motivação dos ciclo turistas no país em 2008/2018 e PE 2019.

Table 4: Motitvation of tourists in the country in 2008/2018 and PE 2019.

\begin{tabular}{cccc}
\hline Ano/Critérios & Natureza/paisagem (\%) & Aventura (\%) & Conhecer novos lugares (\%) \\
\hline Brasil 2008 & 35 & 44 & - \\
Brasil 2018 & 51,4 & 56,7 & - \\
PE 2019 & 24 & - & 50,7 \\
\hline
\end{tabular}

Fonte: elaborado pelos autores (2019).

Source: elaborated by the authors (2019).

\section{Organização da viagem}

Com relação aos gastos durante uma ciclo viagem, o dispêndio máximo diário na sua maioria variou entre $R \$ 30,00$ e 100,00 (Figura 2).

- $2008 \backsim 2018 \backsim$ PE 2019

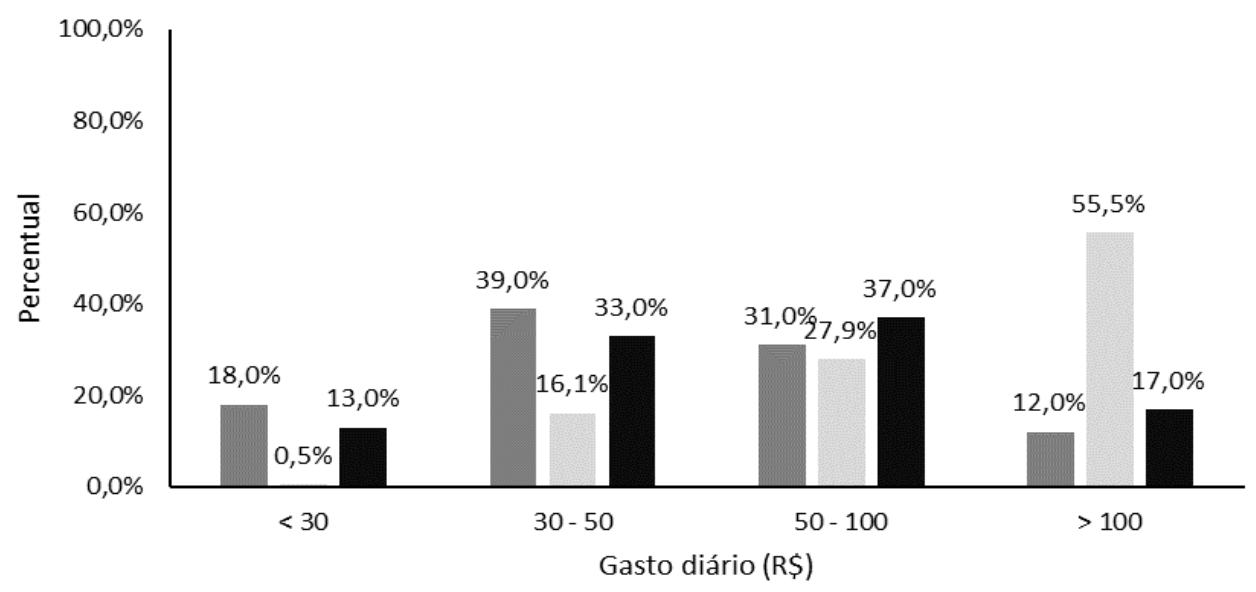

Figura 2: Planejamento financeiro da viagem. Figure 3: Financial Trip Plannig. Fonte: elaborado pelos autores (2019). Source: elaborated by the authors (2019). 
Os ciclo turistas costumam organizar suas viagens tanto com agências especializadas como de forma autônoma (Figura 3A). Já quando o meio de hospedagem é a questão a se perguntar, as opções variam (Figura 3B). Com relação aos meios de alimentação, em ambos os perfis, a preferência é por restaurantes (Figura $3 \mathrm{C}$ ). A respeito da preferência de como cada ciclo viajante coleta suas informações, a maioria prefere apoio da internet e uso de GPS (Figura 3D).

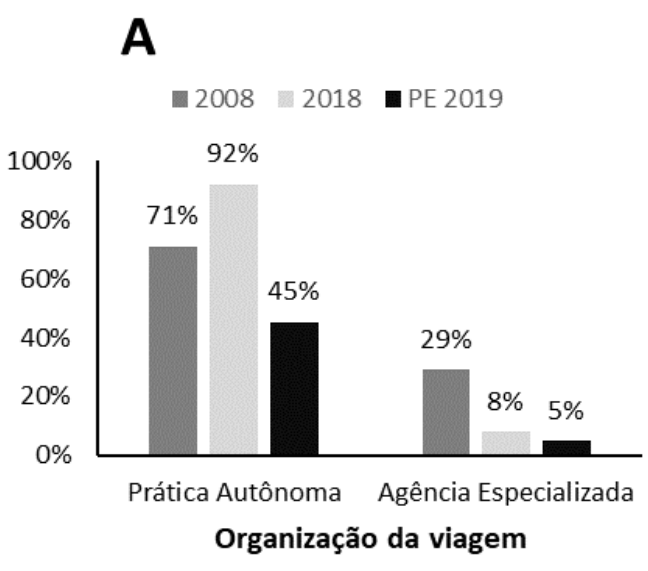

C

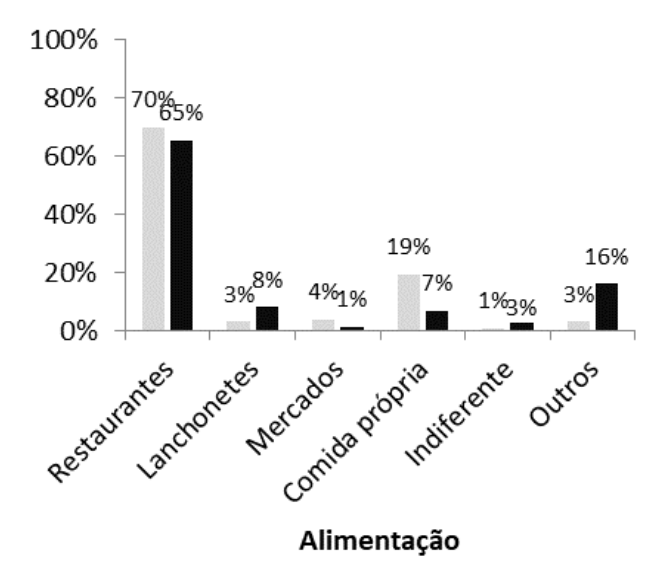

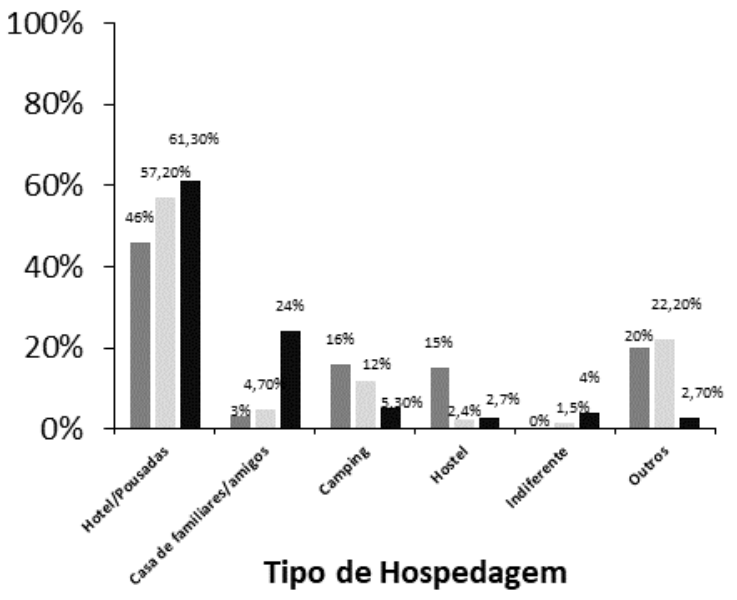

D

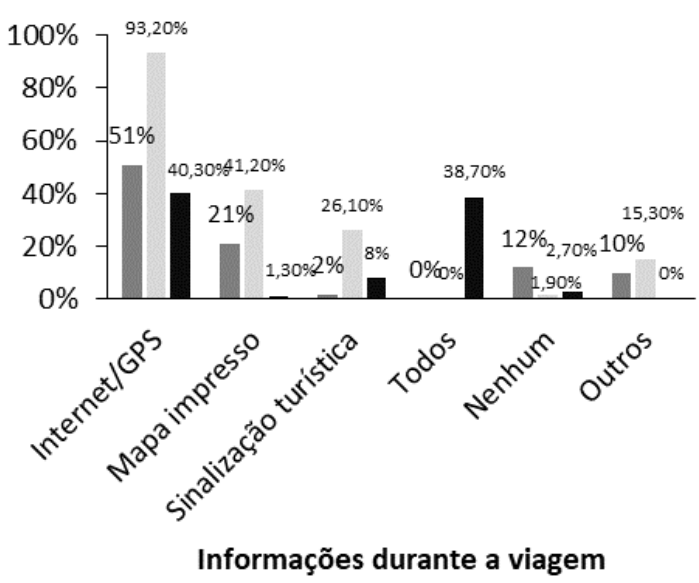

Figura 2: Planejamento da viagem. Figure 2: Trip Plannig.

Fonte: elaborado pelos autores (2019). Source: elaborated by the authors (2019).

$\mathrm{Na}$ parte final da pesquisa sobre as preferências dos ciclo viajantes, $85 \%$ dos entrevistados responderam "natureza/ paisagem"; os demais ficaram no quesito "arquitetura das cidades" e "igrejas/museus". Por último, a pergunta se os ciclo turistas "utilizariam uma rota no interior do estado de Pernambuco?" Obteve 100\% de aceitação. 


\section{Conhecendo mais o ciclo turista de Pernambuco}

Sobre a distância considerada ideal numa viagem, os pernambucanos acham que rotas entre 40 e $100 \mathrm{~km}$ são ideais (Figura 4A). Já quando o quesito foi o tempo gasto para percorrê-la, os percentuais de distribuíram entre 1 e 5 dias (Figura 4B). Já na questão tipo de pista os dados mostram que os praticantes na sua maioria não têm preferência (Figura $4 C$ ).
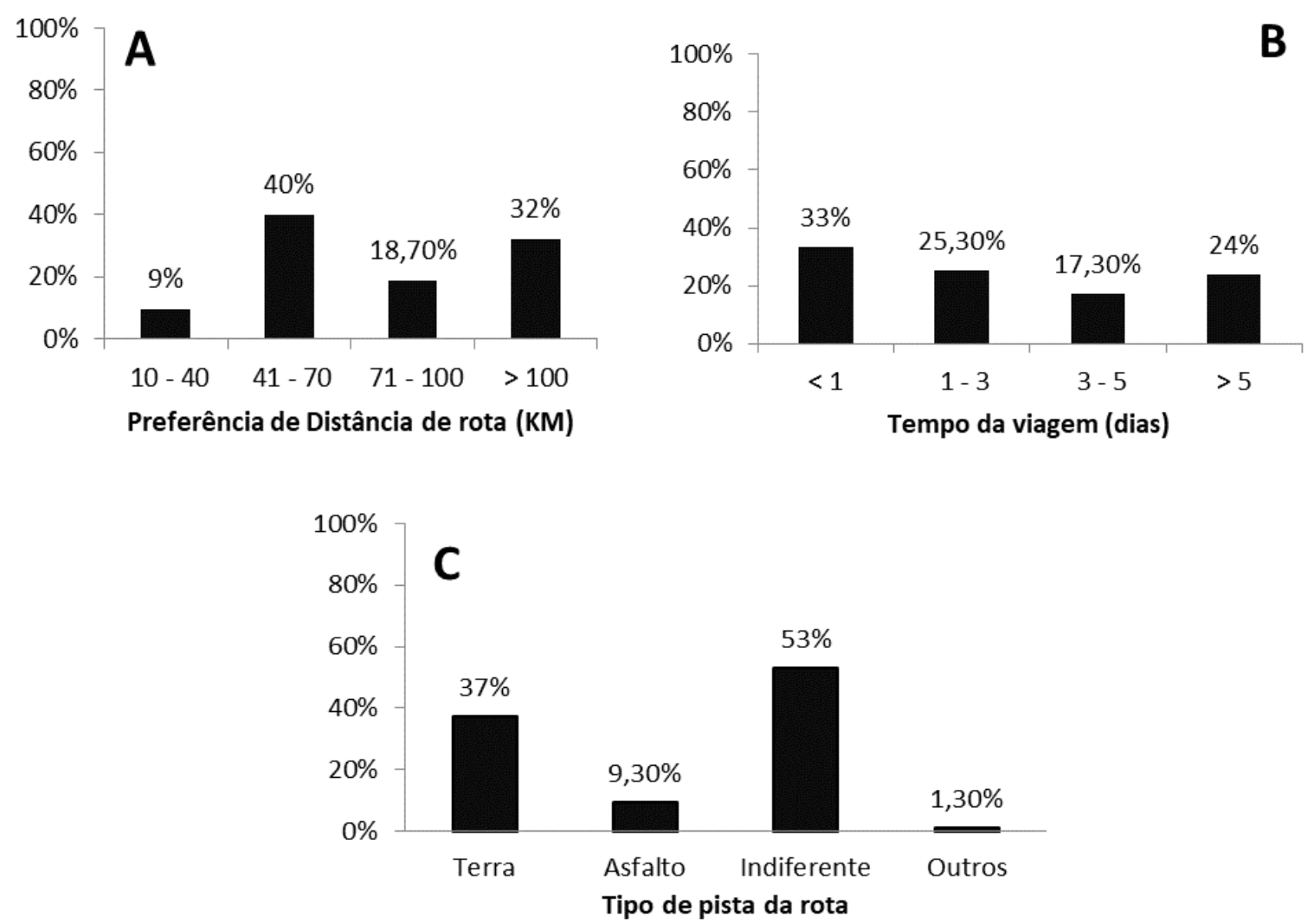

Figura 4: Perfil do ciclo turista de Pernambuco sobre suas preferências numa rota.

Figure 4: Profile of tourist of Pernambuco on your oreferences on a route.

Fonte: elaborado pelos autores (2019).

Source: elaborated by the authors (2019).

\section{A rota do agreste de Pernambuco}

A primeira e única rota de ciclo turismo de Pernambuco, está localizada no agreste do estado e possui $182,60 \mathrm{~km}$ de trilha turística. Está dividida em quatro trechos, sendo eles: de Gravatá para Serra Negra (31 km), de Serra Negra a Caruaru $(31,8 \mathrm{~km})$, de Caruaru a Bonito $(52 \mathrm{~km})$, e de Bonito a Gravatá, passando por Sairé (67,7 km) (ALMEIDA et. al, 2017).

\section{Detalhamento da proposta implantação de uma rota ciclo turística na zona da mata sul de Pernambuco}

Escolheu-se uma região do estado de Pernambuco chamada "Zona da Mata Sul" (Figura 5). Essa área é composta por 24 (vinte quatro) municípios (BDE PE, 2019), que têm a distância da capital Recife variando entre 64 e $144 \mathrm{~km}$ (MDA, 2006) e desempenha papel fundamental na economia do 
estado, perdendo apenas para o Sertão de São Francisco (CAMPELLO et al, 2013) no tocante às atividades turísticas, além de se destacar pela produção agrícola (MDA/SDT, 2011). Aspectos históricos, comunidades tradicionais e recursos naturais abundantes fazem parte da caracterização territorial da região, que justificam a escolha do local para as prospecções.
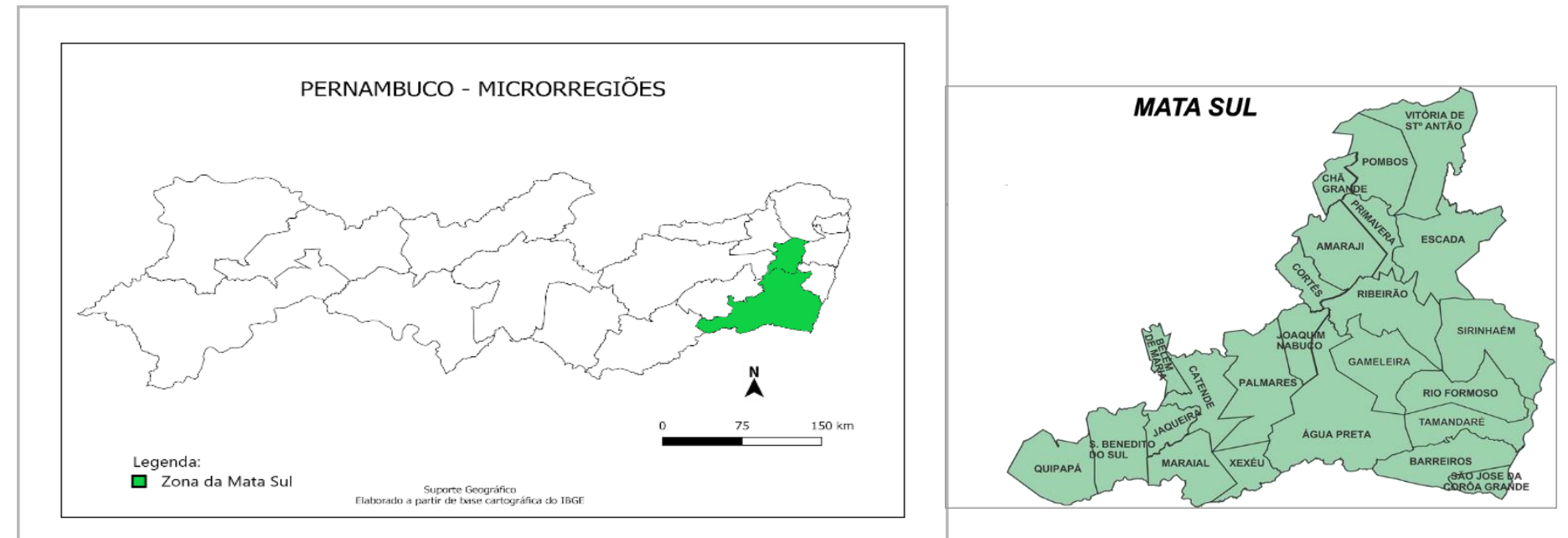

Figura 5: Mapa Zona da Mata Sul de Pernambuco.

Figure 5: South forest of Pernambuco Pernambuco map.

Fonte: Suporte Geográfico (2017). Source: Geographic support (2017).

\section{Definição dos critérios para a projeção de uma rota}

A partir das entrevistas com os ciclo viajantes, 11 subcritérios, que foram subdivididos em 3 critérios Dificuldade da Rota, Recursos Naturais/Culturais e Infraestrutura (Figura 6).

\begin{tabular}{|c|c|c|c|c|c|c|}
\hline Objetivo & & \multicolumn{4}{|c|}{ Criação de Rotas ciclo turísticas na Zona da Mata Sul } & \\
\hline Critérios & \multicolumn{2}{|c|}{ Dificuldade da Rota } & \multicolumn{2}{|c|}{ Recursos Naturais/Culturais } & \multicolumn{2}{|c|}{ Infraestrutura } \\
\hline & lá & ho da Rota & & Temperatura/Clima & Meios de & ospedagem \\
\hline \multirow{3}{*}{ Subcritérios } & Temp & do Percurso & & Natureza/Paisagem & \multicolumn{2}{|c|}{ Pontos de Apoio } \\
\hline & & esso & & História/Cultura & \multicolumn{2}{|c|}{ Infraestrutura Turística } \\
\hline & & tude & & Festa/Eventos & & \\
\hline Municípios & Escada & Palmares & Cortês & Primavera & Catende & Água Preta \\
\hline
\end{tabular}

Figura 6: Definição dos critérios, subcritérios e municípios contemplados na rota. Figure 6: Definition of criteria, of subcriteria and municipalities included in the route. Fonte: elaborado pelos autores (2019). Source: elaborated by the authors (2019).

A primeira matriz de comparação foi entre os critérios e trouxe a relação "par a par" entre a "Dificuldade da Rota", os "Recursos Naturais" e "Infraestrutura". Segundo os especialistas da UFPE, o critério infraestrutura é o mais importante na criação de uma rota $(49,79 \%)$, com o RC abaixo de $20 \%$ demonstrando que a matriz foi preenchida de forma correta e lógica (Tabela $5)$. 
Tabela 5: Prioridade de critérios.

Table 5: Criteria priority.

\begin{tabular}{|c|c|c|c|c|c|c|c|c|c|}
\hline Critérios & $\begin{array}{l}\text { Dificuldade } \\
\text { da Rota }\end{array}$ & $\begin{array}{l}\text { Recursos } \\
\text { Naturais }\end{array}$ & $\begin{array}{c}\text { Infraestrutu } \\
\text { ra }\end{array}$ & $\begin{array}{l}\text { Auto } \\
\text { Vetor }\end{array}$ & V.N. & $\lambda$-Máx & IC & IR & $\mathrm{RC}$ \\
\hline $\begin{array}{c}\text { Dificuldade da } \\
\text { Rota }\end{array}$ & 1,00 & 0,50 & 0,20 & 0,46 & $13,52 \%$ & \multirow{4}{*}{3,09} & \multirow{4}{*}{0,047} & \multirow{4}{*}{0,58} & \multirow{4}{*}{$8,10 \%$} \\
\hline $\begin{array}{l}\text { Recursos } \\
\text { Naturais }\end{array}$ & 2,00 & 1,00 & 1,00 & 1,26 & $36,69 \%$ & & & & \\
\hline Infraestrutura & 5 & 1,00 & 1,00 & 1,71 & $49,79 \%$ & & & & \\
\hline Somatório & 8,00 & 2,50 & 2,20 & 3,43 & $100,00 \%$ & & & & \\
\hline
\end{tabular}

Fonte: elaborado pelos autores (2019).

Source: elaborated by the authors (2019).

A partir da média ponderada entre os 4 (quatro) critérios e os 11 (onze) subcritérios, ficou definido que os subcritérios mais importantes segundo a especialista, foram: Natureza/ Paisagem, Meios de Hospedagem, Pontos de Apoio e Infraestrutura Turística, (Tabela 6).

Tabela 6: Percentuais Finais dos subcritérios.

Table 6: Final percentages of the subcriteria.

Critérios

Hierarquia dos critérios

\begin{tabular}{lll}
\hline $\begin{array}{l}\text { Dificuldade da Rota } \\
\text { Recursos Naturais } \\
\text { Infraestrutura }\end{array}$ & & $\begin{array}{r}13,52 \% \\
36,69 \% \\
49,79 \%\end{array}$ \\
\hline & & \\
Dificuldade da Rota & Percentual das matrizes dos & Percentual final \\
Tamanho da rota & $42,75 \%$ & $6 \%$ \\
Tempo de percurso & $42,75 \%$ & $6 \%$ \\
Tipo de pista & $7,86 \%$ & $1 \%$ \\
Altimetria & $6,64 \%$ & $1 \%$
\end{tabular}

Recursos Naturais/culturais

Temperatura ideal

Paisagem/ Natureza

História/ cultura do local

Eventos/ Festas populares

\section{Infraestrutura}

Meios de Hospedagem

Pontos de Apoio

Infraestrutura Turística
Percentual das matrizes dos subcritérios

$10,00 \%$

$70,00 \%$

$10,00 \%$

$10,00 \%$

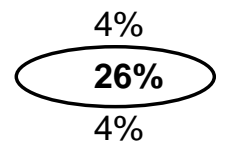

$4 \%$

Percentual das matrizes dos subcritérios

$33 \%$

$33 \%$

$33 \%$

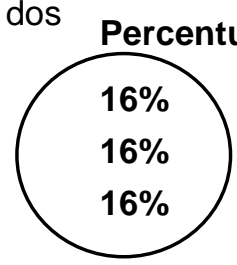

$100 \%$

Somatória da Coluna

Fonte: elaborado pelos autores (2019).

Source: elaborated by the authors (2019). 


\section{Paisagem e natureza}

Segundo o manual de incentivo e orientação para os municípios brasileiros para circuito de ciclo turismo, considerou-se como "Natureza/Paisagem": "Cachoeiras, parques ecológicos, florestas, zoológicos, jardins botânicos e hortos, montanhas e mirantes" (GOVERNO DE SANTA CATARINA, 2010). Foi feito um levantamento em cada município da região estudada. O município que possuía pelo menos um atrativo em questão foi marcado com um $(X)$, enquanto um traço (-) representou que não foi encontrado informação sobre esse atrativo na região. Para calcular o percentual da coluna "total", dividiu-se a quantidade de atrativos de cada município por 6 (seis), que foi o total dos atrativos considerados. Exemplo: Amaraji tem 3 (três) atrativos: (Cachoeiras, Rios e Reservas florestais) do total de 6 (seis) tipos possíveis (Cachoeira, Rios, Parques Ecológicos, Reservas florestais, Corredeiras e Bicas), o que totalizaria $50 \%$ dos atrativos.

Portando, a partir do critério mais votado (Paisagem/Natureza) realizou-se um levantamento com elementos que caracterizam esse critério para eleger os 7 (sete) municípios com porcentagens maiores que 50\%, sendo eles: Água preta, Catende, Palmares, Quipapá, Primavera, Escada e Cortês e a partir disso fazer as demais avaliações (Tabela 7).

Tabela 7: Paisagem/Natureza.

Table 7: Landscape/Nature.

\begin{tabular}{|c|c|c|c|c|c|c|c|}
\hline $\begin{array}{l}\text { Natureza/ } \\
\text { Paisagem }\end{array}$ & Cachoeiras & Rios & $\begin{array}{c}\text { Parques } \\
\text { Ecológicos }\end{array}$ & $\begin{array}{l}\text { Reservas } \\
\text { Florestais }\end{array}$ & Corredeiras & Bicas & Total \\
\hline Água Preta & $\mathrm{X}$ & $\mathrm{X}$ & $\mathrm{X}$ & $\mathrm{X}$ & $\mathrm{X}$ & $\mathrm{X}$ & $100,00 \%$ \\
\hline Amaraji & $\mathrm{x}$ & $\mathrm{x}$ & - & $\mathrm{x}$ & - & - & $50,00 \%$ \\
\hline Barreiros & - & $\mathrm{X}$ & - & - & $\mathrm{X}$ & $\mathrm{x}$ & $50,00 \%$ \\
\hline Belém de Maria & - & $x$ & - & - & $x$ & - & $33,33 \%$ \\
\hline Chã Grande & $\mathrm{X}$ & $x$ & - & - & - & - & $33,33 \%$ \\
\hline Cortês & $\mathrm{x}$ & $x$ & - & - & $x$ & $x$ & $66,67 \%$ \\
\hline Catende & $\mathrm{X}$ & $\mathrm{x}$ & - & $\mathrm{X}$ & $\mathrm{x}$ & $x$ & $83,33 \%$ \\
\hline Escada & $x$ & $\mathrm{X}$ & - & $\mathrm{x}$ & $\mathrm{x}$ & $\mathrm{x}$ & $83,33 \%$ \\
\hline Gameleira & - & - & - & - & - & - & $0,00 \%$ \\
\hline Joaquim Nabuco & - & - & - & - & - & - & $0,00 \%$ \\
\hline Jaqueira & - & $x$ & - & - & - & - & $16,67 \%$ \\
\hline Maraial & $\mathrm{X}$ & $x$ & - & - & - & - & $33,33 \%$ \\
\hline Pombos & - & $x$ & - & - & - & - & $16,67 \%$ \\
\hline Primavera & $\mathrm{X}$ & $X$ & $\mathrm{X}$ & - & $\mathrm{x}$ & $\mathrm{X}$ & $83,33 \%$ \\
\hline Palmares & $x$ & $x$ & - & - & $\mathrm{x}$ & $\mathrm{x}$ & $66,67 \%$ \\
\hline Quipapá & $x$ & $\mathrm{x}$ & - & $\mathrm{x}$ & $\mathrm{x}$ & $\mathrm{x}$ & $83,33 \%$ \\
\hline Ribeirão & $x$ & $\mathrm{x}$ & - & - & - & $\mathrm{x}$ & $50,00 \%$ \\
\hline Rio Formoso & $x$ & $x$ & - & - & $x$ & - & $50,00 \%$ \\
\hline Sirinhaém & $\mathrm{X}$ & $\mathrm{x}$ & - & - & - & $\mathrm{X}$ & $50,00 \%$ \\
\hline $\begin{array}{l}\text { São José da } \\
\text { Coroa Grande }\end{array}$ & - & $x$ & - & $x$ & - & - & $33,33 \%$ \\
\hline $\begin{array}{l}\text { São Benedito do } \\
\text { Sul }\end{array}$ & $x$ & - & - & - & $x$ & $x$ & $50,00 \%$ \\
\hline Tamandaré & $\mathrm{X}$ & $x$ & - & $\mathrm{X}$ & - & - & $50,00 \%$ \\
\hline $\begin{array}{l}\text { Vitória de Santo } \\
\text { Antão }\end{array}$ & - & - & - & - & - & - & $0,00 \%$ \\
\hline Xexéu. & - & $x$ & - & - & - & - & $16,67 \%$ \\
\hline
\end{tabular}

Fonte: elaborado pelos autores (2019).

Source: elaborated by the authors (2019). 


\section{Meios de hospedagem}

Seguindo o que descreve o Art. 23, Lei $n^{0} 11.771$, de 17 de setembro de 2008 os "Meios de Hospedagem" foram subdivididos em Pousada, Hotel, Hostel (Albergue) e Camping, segundo as preferências informadas pelos ciclo turistas. Seguindo a mesma lógica do levantamento anterior, realizou-se um diagnóstico entre os sete municípios que possuíam esses tipos de hospedagem, por meio dos sites: INVTUR-PE, AIRBNB, BOOKING, TRIVAGO e TRIPSADVISOR (Tabela 8).

Tabela 8: Meios de hospedagem nos municípios selecionados na Mata Sul de Pernambuco.

Table 8: Accommodation facilities in selected municipalities in the south forest of Pernambuco.

\begin{tabular}{lccccc}
\hline $\begin{array}{l}\text { Meios de } \\
\text { Hospedagem }\end{array}$ & Pousada & Hotel & $\begin{array}{c}\text { Hostel } \\
\text { (Albergue) }\end{array}$ & Camping & Total \\
\hline Água Preta & $\mathrm{X}$ & $\mathrm{X}$ & - & - & $50,00 \%$ \\
Cortês & $\mathrm{X}$ & - & - & - & $25,00 \%$ \\
Catende & - & $\mathrm{X}$ & $\mathrm{X}$ & - & $50,00 \%$ \\
Escada & $\mathrm{X}$ & - & $\mathrm{X}$ & - & $50,00 \%$ \\
Primavera & - & $\mathrm{X}$ & $\mathrm{X}$ & - & $50,00 \%$ \\
Palmares & $\mathrm{X}$ & $\mathrm{X}$ & $\mathrm{X}$ & - & $75,00 \%$ \\
Quipapá & $\mathrm{X}$ & - & - & $\mathrm{X}$ & $50,00 \%$
\end{tabular}

Fonte: elaborado pelos autores (2019).

Source: elaborated by the authors (2019).

Nenhum município selecionado apresentou $100 \%$ das opções, sendo o município de Palmares o que apresentou mais capacidade de hospedagem. Segundo o estudo de "Mapie" realizado com 880 pessoas de todo o país, em relação aos meios de hospedagem: "para os viajantes, a localização é fator determinante. A segurança, a qualidade do serviço, a facilidade na reserva/compra e experiências positivas anteriores aparecem logo depois como critérios importantes para se fechar o negócio" (MAPIE CONSULTURIA, 2016). Nesse quesito, a vantagem está novamente no município de Palmares.

\section{Pontos de apoio}

Para o Glossário de turismo (2018, p.18) pontos de apoio é: "Conjunto de obras, de estrutura física e serviços que proporciona boas condições de vida para com a comunidade e dá base para o desenvolvimento da atividade turística". Os dados foram coletados pelo site do INVTUR-PE e pelo site do Correios, que demonstraram que o único município que não atingiu $100 \%$ foi Cortês (Tabela 9).

Tabela 9: Pontos de Apoio nos municípios selecionados na Mata Sul de Pernambuco.

Table 9: Support points in selected municipalities in the south forest of Pernambuco.

\begin{tabular}{|c|c|c|c|c|c|}
\hline Pontos de Apoio & Correios & Bancos & Posto de saúde & Farmácias & Total \\
\hline Água Preta & $\mathrm{X}$ & $\bar{X}$ & $\mathrm{X}$ & $\mathrm{X}$ & $100,00 \%$ \\
\hline Cortês & $\mathrm{X}$ & - & $x$ & $X$ & $75,00 \%$ \\
\hline Catende & $\mathrm{X}$ & $x$ & $x$ & $X$ & $100,00 \%$ \\
\hline Escada & $x$ & $x$ & $x$ & $x$ & $100,00 \%$ \\
\hline Primavera & $x$ & $x$ & $x$ & $X$ & $100,00 \%$ \\
\hline Palmares & $x$ & $x$ & $x$ & $x$ & $100,00 \%$ \\
\hline Quipapá & $\mathrm{X}$ & $X$ & $\mathrm{X}$ & $\mathrm{X}$ & $100,00 \%$ \\
\hline
\end{tabular}

Fonte: elaborado pelos autores (2019). Source: elaborated by the authors (2019). 


\section{Infraestrutura turística}

Diversos itens fazem parte da infraestrutura turística que se caracteriza por ser um "Conjunto formado por obras e instalações de estrutura física e de serviços, indispensáveis ao desenvolvimento do turismo e existentes em função dele" (Glossário de turismo, 2018, p.18). Entretanto, foram usados os mesmos que o INVTUR-PE: "Meios de alimentação" e "Operadora/Agência de Viagens" (Tabela 10).

Tabela 10: Infraestrutura Turística nos municípios selecionados na Mata Sul de Pernambuco. Table 10: Tourism infrastructure in selected municipalities in the south forest of Pernambuco.

\begin{tabular}{ll}
\hline Infraestrutura & Meios \\
Turística & alime \\
\hline Água Preta & \\
Cortês & \\
Catende & \\
Escada & \\
Primavera & \\
Palmares & \\
Quipapá &
\end{tabular}

Operadora / Agência de Viagens alimentação

Fonte: elaborado pelos autores (2019).

Source: elaborated by the authors (2019).

\section{Descrição das rotas finais}

Depois de se eleger os 7 municípios a partir da análise dos critérios e subcritérios, pôde-se avaliar suas proximidades, o que não impede que outros municípios limítrofes façam parte da rota (Figura 7).

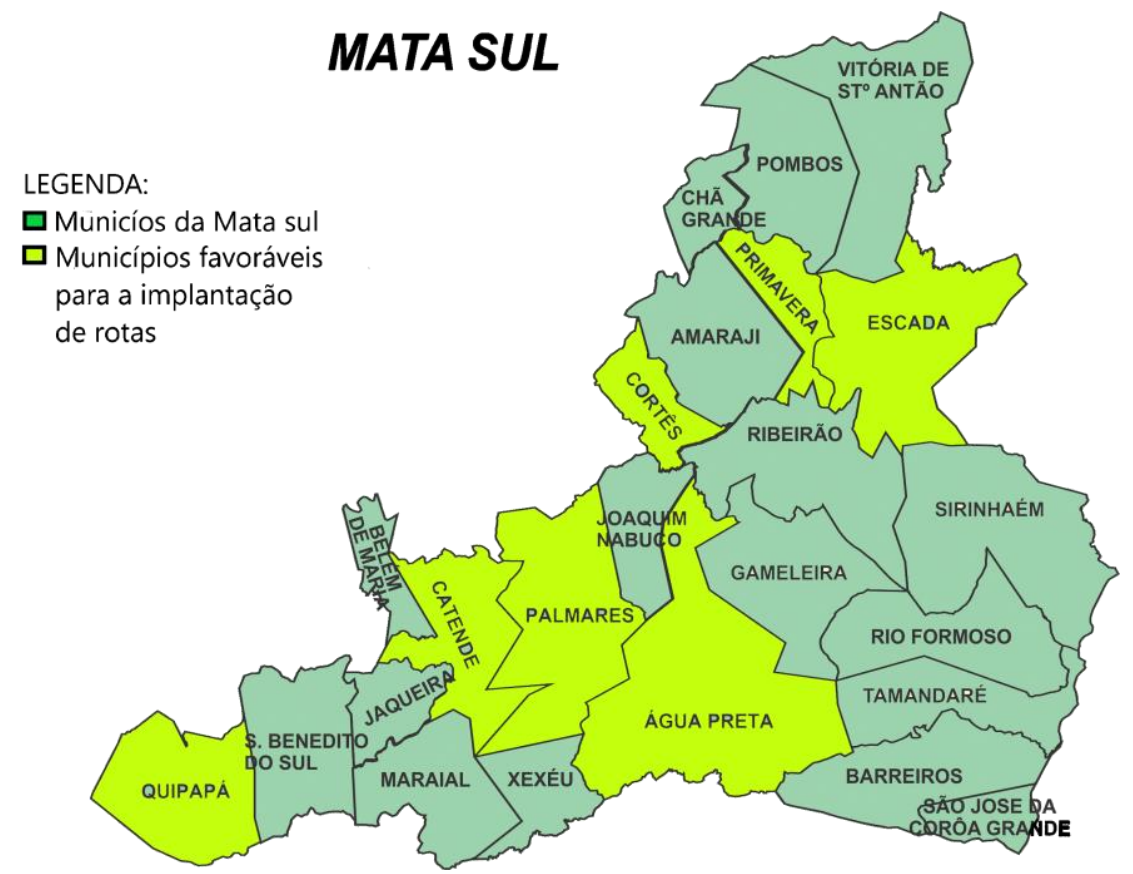

Figura 7: Mapa com os municípios favoráveis para a implantação de rotas.

Figure 7: Map with favorable municipalities for the implementations of routes.

Fonte: elaborado pelos autores (2019). Source: elaborated by the authors (2019). 


\section{Rota Água Preta / Quipapá}

A primeira rota começa no município de Água Preta, passando por Palmares, Catende, Jaqueira, São Benedito do Sul e Quipapá. Apenas um trecho pequeno entre Água Preta e Palmares passam pela BR-101, a outra parte do percurso é pela PE- 096 e PE-126. A rota terá cerca de $68 \mathrm{~km}$, dentro da variação de 40 a $70 \mathrm{~km}$ preferidos pelos ciclo turistas de Pernambuco (Figura 8).

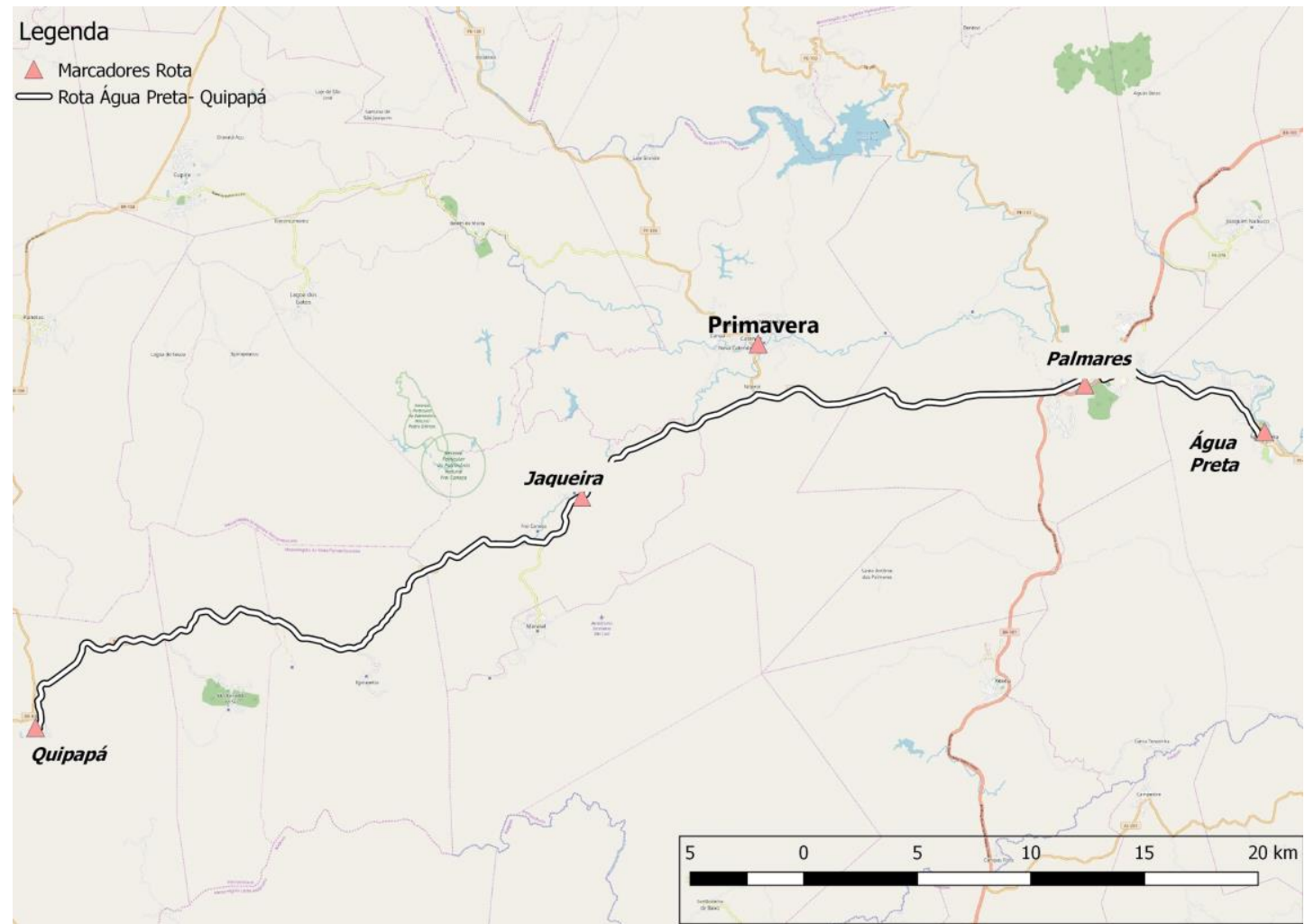

Figura 8: Mapa da Rota Água Preta / Quipapá (Google Earth e QGIS).

Figure 8: Map of route Água Preta / Quipapá (Google Earth e QGIS).

Fonte: elaborado pelos autores (2019).

Source: elaborated by the authors (2019).

\section{Rota Escada / Cortês}

A segunda rota projetada utilizou do Google Maps para conectar os municípios de Escada, Primavera, Amaraji e Cortês com $54,5 \mathrm{~km}$ de extensão. Pode-se optar por dois percursos, com o primeiro se utilizando da PE 063 direto para a rota ou escolher aumentar o percurso pela PE 071 e PE 085, entre Amaraji e Cortês, chegando a 78,9 km (Figura 9). 


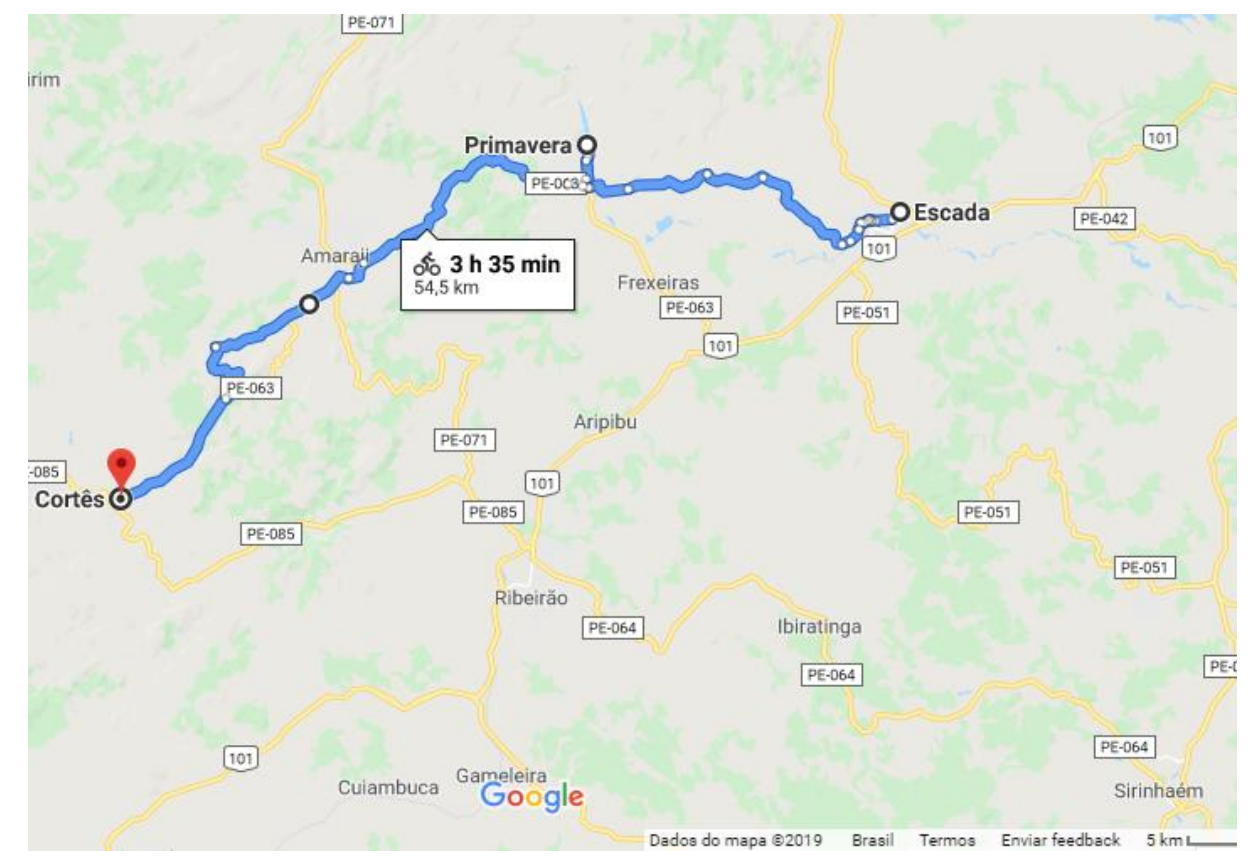

Figura 9: Mapa da rota Escada / Cortês (Google Maps).

Figure 9: Map of route Escada / Cortês (Google Maps).

Fonte: elaborado pelos autores (2019). Source: elaborated by the authors (2019).

\section{Rota Escada / Quipapá}

A terceira rota sugerida seria ligando os sete municípios que melhor atingiram os critérios, totalizando $168 \mathrm{~km}$ de extensão entre Escada e Quipapá. A rota utilizaria a PE 063, PE 126 e PE 085. Outros municípios se encontram na rota como Amaraji, Joaquim Nabuco, São Benedito do Sul e Jaqueira, que podem servir como pontos de apoio além de possuir belezas naturais próprias. Essa rota pode atrair ciclo turistas nacionais, com preferência por rotas com maiores percursos e com maiores tempos de permanência (Figura 10).

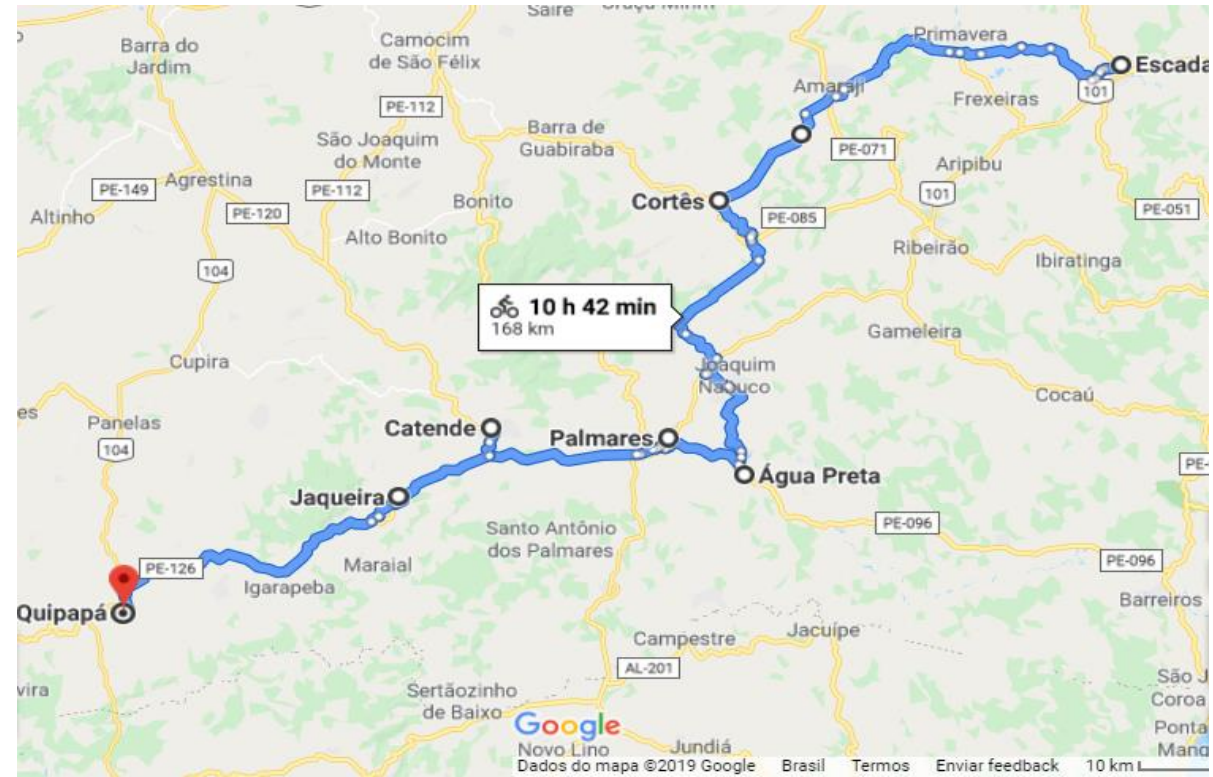

Figura 10: Rota ligando todos os municípios escolhidos (Google Maps).

Figure 10: Route liking all the chosen municipalities (Google Maps).

Fonte: elaborado pelos autores (2019). Source: elaborated by the authors (2019). 


\section{Considerações finais}

O ciclo turismo pode não ter uma definição universal aceita ou muitos estudos acadêmicos sobre a atividade, mas sua prática está mudando o modo de fazer turismo no mundo, tornando necessário o aprofundamento de pesquisas.

A escolha do método de processo hierárquico analítico (AHP), foi essencial para conseguir definir os principais critérios para implantar de uma futura rota.

Portanto, este trabalho deixa como contribuição, um modo de utilizar uma atividade turística para a regionalização do turismo e desenvolvimento de municípios além de servir como base para empregar o método em outras mesorregiões de Pernambuco, como possíveis pesquisas futuras.

\section{Referências}

BDE, PE. Base de dados do Estado de Pernambuco. Relação dos municípios que compõem a Zona da Mata Sul. Disponível em: $<$ http://www.bde.pe.gov.br/visualizacao/Visualizacao formato2.aspx?Codlnfor macao=798\&Cod=1 > Acesso em agosto de 2019.

BRASIL, MINISTÉRIO DO TURISMO. GLOSSÁRIO DE TURISMO. Compilação de termos publicados por Ministério do Turismo e Embratur nos últimos 15 anos. Brasília, Ministério do Turismo, 44 p., 2018.

CAMARGO, L. J. J.; CAMARGO, C. M. J.; RONDON, E. V.; QUEIROZ, H. P. B.; SANTOS, S. R., FAVERO, S., MERCANTE, M. A. Análise da sustentabilidade do turismo ecológico no município de Bonito, Mato Grosso do Sul na promoção do desenvolvimento regional. Sociedade \& Natureza, Uberlândia, v. 23, n 1 p.65-75, 2011.

FAVRETTO, J.; NOTTAR, L. A. Utilização da metodologia Analytic Hierarchy Process (AHP) na definição de um software acadêmico para uma instituição de ensino superior do Oeste Catarinense. Revista Sistemas \& Gestão, v. 11, n. 2, 2016.

GOUVEIA, L. A.; GOSLING, M.; COELHO, M. F.; PEREIRA, G. A. Fatores que influenciam a intenção de compra de viagens de ecoturismo e turismo de aventura. Revista Brasileira de Ecoturismo, São Paulo, v.7, n.3, p.551-575, 2014.

GOVERNO DE SANTA CATARINA. Circuito de ciclo turismo: Manual de incentivo e orientação para os municípios brasileiros. UDESC Universidade do Estado de Santa Catarina, 19 p., 2010.

LEE, T. H. A. Structural Model to Examine How Destination Image, Attitude, and Motivation Affect the Future Behavior of Tourists. Leisure Sciences, v. 31, n. 3, p. 215-236, 2009. 
MAPIE CONSULTORIA. O futuro da hotelaria. Revista Hotelnews, São Paulo, abril de 2016.2 Disponível em:<https://www.revistahotelnews.com.br/mapie-lanca-pesquisa-sobre-ofuturo-da-hotelaria/>. Acesso em: agosto de 2019.

MARANHÃO, C. H. S.; AZEVEDO, F. F. A Representatividade do Ecoturismo para a gestão pública do turismo no Brasil: uma análise do Plano Nacional de Turismo 2018-2022. Revista Brasileira de Ecoturismo, São Paulo, v.12, n.1, pp.09-35, 2019.

MARTINS, C. I. M. Turismo Rural e Desenvolvimento Sustentável O Papel da Arquitetura Vernacular. Dissertação (Mestrado em Arquitetura) Universidade da Beira Interior,Covilhã, Portugal, p. 161, 2012.

MERCE, I. I.; MILIN, I. A.; MILIN, S.; DANCEA, L.; LANCU, T.; SÂMBOTIN, D. Study on development and trends of ecotourism in Romania. Agricultural Management / Lucrari Stiintifice Seria I, Management Agricol, v. 14, n. 4, p. 351-356, 2012.

MINISTÉRIO DO TURISMO. Inventário da Oferta Turística / Ana Clévia Guerreiro Lima (Coordenador) - Brasília, 38 p., 2011.

PCR. Malha cicloviária do Recife. Prefeitura do Recife, Recife, maio de 2020. Disponível em:<http://dados.recife.pe.gov.br/ne/dataset/malhacicloviaria-do-

recife\#: : :text=S\%C3\%A30\%20170\%20quil\%C3\%B4metros\%20de\%20ciclovia s,funcionam\%20aos\%20domingos\%20e\%20feriados.\&text=No\%20Recife\%2 C\%20as\%20ciclofaixas\%20que, se\%20caracterizam\%20como\%20Ciclofaixas \%200peracionais> Acesso em: agosto de 2020.

REVISTA BICICLETA. Os benefícios de andar de bicicleta. Disponível em: $<$ http://www.revistabicicleta.com.br/bicicleta noticia.php?os beneficios de an dar de bicicleta\&id=31258 >. Acesso em: 10 nov. 2018.

SAATY, T. L. Analytic Hierarchy Process, New York, MCGraw - Hill, 1980.

SAATY, T. L. Fundamentals of Decision Making and Priority Theory with AHP. Pittsburgh USA, RWS Publications, 330 p., 1994.

SEBRAE. Turismo rural em Pernambuco. SEBRAE Recife, 66 p., 2011.

VELASCO, C., Ramalho, G.; Massuella, L.; Reis, T.; G1; GloboNews. Malha cicloviária das capitais cresce $133 \%$ em 4 anos e já passa de 3 mil quilômetros. Caderno de Economia G1. São Paulo, agosto de 2018. Disponível em: <https://g1.globo.com/economia/noticia/2018/08/28/malhacicloviaria-das-capitais-cresce-133-em-4-anos-e-ja-passa-de-3-mil-

quilometros.ghtml>. Acesso em: março de 2019. 
Thales Ramon de Queiroz Bezerra: Instituto Federal de Pernambuco, Recife, PE, Brasil.

E-mail: thales_ramon@hotmail.com

Link para o currículo Lattes: http://lattes.cnpq.br/4731505337833549

Emily Cristine de Aguiar Costa: Instituto Federal de Pernambuco, Recife, PE, Brasil.

E-mail: emilly.aguiar1@gmail.com

Link para o currículo Lattes: http://lattes.cnpq.br/3298976757086601

Data de submissão: 09 de março de 2021

Data de recebimento de correções: 28 de julho de 2021

Data do aceite: 28 de julho de 2021

Avaliado anonimamente 